\title{
The efficacy and safety of a single maintenance laser treatment for stress urinary incontinence: a double-blinded randomized controlled trial
}

\author{
Roy Lauterbach $^{1}$ (D) $\cdot$ Saar Aharoni ${ }^{1} \cdot$ Naphtali Justman $^{1} \cdot$ Naama Farago ${ }^{1} \cdot$ Ilan Gruenwald $^{1,2} \cdot$ Lior Lowenstein $^{3,4}$
}

Received: 5 December 2021 / Accepted: 14 January 2022 / Published online: 23 February 2022

(c) The International Urogynecological Association 2022

\begin{abstract}
Introduction and hypothesis To evaluate the efficacy and safety of a single carbon dioxide $\left(\mathrm{CO}_{2}\right)$ laser maintenance treatment in women previously treated successfully with laser for stress urinary incontinence (SUI), who have demonstrated a decline in treatment effect.

Methods Women aged 40-70 years who experienced temporary significant improvement in symptoms following $\mathrm{CO}_{2}$ laser treatments for SUI were randomized to either the treatment group or the sham treatment control group. Cough test results, 1-h pad weights and scores on the Urogenital Distress Inventory (UDI6), the International Consultation of Incontinence Questionnaire (ICIQ-UI) and the Pelvic Organ Prolapse/Urinary Incontinence Sexual Questionnaire (PISQ-12) were obtained at baseline and 3 and 6 months.

Results Of 183 women screened, 131 were included in the final analysis. Demographic characteristics and baseline measures in the outcome tests were similar between the groups. Statistically significant improvements were demonstrated in the study compared to the control group at 3 months post-treatment in positive cough test $(44.4 \%$ vs. $79.4 \%, P=0.002)$, mean pad weight test $(2.3 \mathrm{~g} \pm 1.3$ vs. $5.6 \pm 1.1, P<0.001)$, mean UDI-6(24.7 \pm 12.1 vs. $45.1 \pm 13.6 \mathrm{SD}, P=0.004)$, mean ICIQ-UI $(16.5 \pm 4.3$ vs. $10.3+3.8, P=0.003)$ and mean PISQ-12 $(21.3 \pm 6.8$ vs. $36.6 \pm 7.5, P=0.003)$. However, values at 6 months post-treatment were similar to those at baseline.

Conclusions Our results suggest that a single maintenance laser treatment for reducing symptoms of SUI is transiently effective, well tolerated and safe. This treatment modality provides alternative non-surgical therapy for women with SUI.
\end{abstract}

Keywords Efficacy $\cdot$ Carbon dioxide laser $\cdot$ Laser treatment $\cdot$ Maintenance $\cdot$ Safety $\cdot$ Stress urinary incontinence

\section{Introduction}

The reported prevalence of stress urinary incontinence (SUI) is $30 \%-65 \%$ worldwide [1-3]. The substantial effect of SUI on quality of life represents a considerable economical and

Roy Lauterbach

r_lauterbach@rambam.health.gov.il

1 Department of Obstetrics and Gynecology, Rambam Health Care Campus, 3109601 Haifa, Israel

2 Bruce Rappaport Faculty of Medicine, Technion-Israel Institute of Technology, Haifa, Israel

3 Department of Obstetrics and Gynecology, Galilee Medical Center, Nahariya, Israel

4 Azrieli Faculty of Medicine, Bar-Ilan University, Safed, Israel psychological burden $[4,5]$. Current non-surgical treatments include physical therapy, lifestyle modifications and pessary application [3, 6]. These options offer temporary improvement in symptoms and lack efficacy in women with severe symptoms [6]. Surgical treatment with suspension surgery or the use of mid-urethral slings offers high and long-term efficacy at a risk of surgical complications [4-9].

Previous case series have demonstrated mixed results regarding the potential efficacy of laser therapy for treating pelvic organ prolapse, genitourinary syndrome of menopause and sexual function, and several studies that utilized sub-optimal methodology have demonstrated mixed results regarding the potential efficacy of $\mathrm{CO}_{2}$ laser for treatment of SUI [10-17]. The main flaw of most studies regarding laser use for benign gynecological indications is the prominent lack of a control or sham group. 
While most studies reported significant treatment efficacy, long-term follow-up was not available, and the few studies that reported 6-12-month follow-up demonstrated a decline in treatment effect to baseline level [14, 16, 18]. Only a few studies reported objective evaluation of symptoms measured with urodynamic testing and the cough test [19].

To date, no data have been published regarding the efficacy and safety of adjuvant treatments. Furthermore, the European Society of Sexual Medicine, the International Urogynecology Association and the International Continence Society state that it is too early, based on the current research of laser-based treatments, to make any decisive recommendations regarding the role of lasers in treatment of benign gynecological pathologies. In addition, the lack of RCTs with proper design and analysis for safety endpoints and short- and long-term benefits is quite prominent [20, 21]. To further emphasize the uncertainty regarding the safety and efficacy of laser treatments in the field of gynecology, in July 2019 the Food and Drug Administration (FDA) issued warnings regarding the required caution in interpreting laser study results and other vaginal rejuvenation procedures in addition to claims of false marketing made against several commercial laser companies [22].

This study aims to evaluate the efficacy and safety of a single laser maintenance treatment in women previously treated successfully with laser for SUI who experienced a decline in treatment effect in the setting of a RCT.

\section{Materials and methods}

\section{Study design and participants}

This was a double-blinded, prospective RCT conducted between June 2019 and February 2020. The trial ended after the completion of recruitment and the follow-up period. The trial was approved by the local ERB and was registered in clinicaltrials.com prior to patient recruitemnt (NCT04111952; https://clinicaltrials.gov/ct2/show/NCT04 111952). All the women who participated in the study signed written informed consent forms.

Study inclusion criteria were age 40-70 years, previous treatment with $\mathrm{CO}_{2}$ laser due to SUI at the laser clinic in a tertiary medical center and a temporary significant improvement in symptoms following the treatments based on minimal important differences of both the Urogenital Distress Inventory (UDI6) and the Pelvic Organ Prolapse/Urinary Incontinence Sexual Questionnaire (PISQ-12) [23-25]. Women were referred from the continence clinic after assessment by an urogynecologist that included a urine culture, Pap smear, cough test and pad test, in addition to a thorough gynecological examination. Exclusion criteria included the following: pregnancy, current or recurrent urinary tract infections or pelvic inflammatory disease, previous vaginal surgery (including surgery for the treatment of SUI), mixed urinary incontinence, treatment with systemic or vaginal estrogen/DHEA/testosterone (or herbal substances that may contain hormonal derivatives) and unexplained vaginal bleeding prior to the initiation of the study.

\section{Study intervention}

Women who met the study eligibility criteria were randomized using a computerized randomization scheme by the research coordinator (block size of 8); randomization results were sealed in an opaque envelope and the treating physician was notified regarding the randomized treatment prior to the therapy session. Allocation was to one of two groups: (1) study group with a single laser treatment; (2) control group with a single sham laser treatment. The Lumenis AcuPulse System using the FemTouch vaginal hand piece (cleared by the ministry of health in the country where the study was conducted for benign gynecological indications) was used during the study. Laser therapy was delivered circumferentially to the entire length of the vaginal epithelial surface. Laser settings were set to an energy level of $12.5 \mathrm{~m}$ joules and a density of $10 \%$. The duration of treatment was up to $5 \mathrm{~min}$. Treatment performance was undertaken by a single physician who was blinded to any patient information and did not converse with the patient before, during or after the treatment. Pain was evaluated during and after the treatment according to a 10-point visual analogue scale. The participants were instructed to refrain from vaginal intercourse and tampon use for 14 days following treatment. They were evaluated 3 and 6 months after completion of the allocated treatment.

\section{Study outcomes}

The primary outcomes were changes in cough test results, 1-h pad weight test results and scores on the UDI6, PISQ-12 and International Consultation of Incontinence Questionnaire (ICIQ-UI). These questionnaires are widely accepted, validated, global assessment tools that have been commonly used in SUI studies. The ICIQ-UI accesses reasons for SUI, incidence, frequency and impact on daily lifestyle. The maximal score is 21 , and a higher score indicates substantial impact. The UDI6 questionnaire comprises six questions regarding urinary frequency, urgency, amount of leakage, difficulty emptying the bladder and pain. The range of scores is $0-75$; a higher score indicates worse symptoms. The PISQ-12 questionnaire evaluates the impact of incontinence on sexual function. The range of scores is $0-48$; a higher score indicates a substantial negative impact of symptoms. All the participants filled the questionnaires during the screening visit (baseline) and 3 and 6 months post-treatment. 
All the participants underwent a cough test and a pad weight test before the treatment and during the 3- and 6-month follow-up visits. Adverse events were recorded at each study interval. Pain was assessed based on a 10 -point visual analogue scale (VAS) following each treatment.

\section{Statistical analyses}

The study data were organized and analyzed using the 27th version of SPSS for Windows (SPSS, Inc., Chicago, IL). Independent groups of continuous variables and categorical variables were compared based on the independent $t$ - and chi-square of association tests, respectively. All tests were two sided and were considered significant at a 0.05 level. Sample size was based on previous studies that demonstrated the minimal important difference of each of the abovementioned questionnaires including the UDI-6 entailing an MID

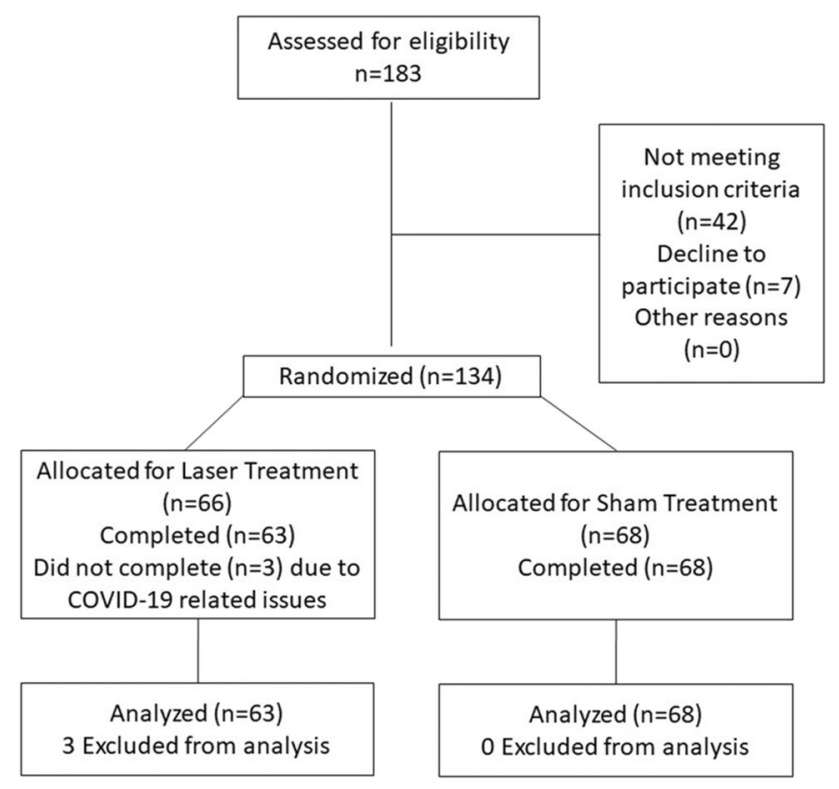

Fig. 1 Flowchart of patient enrollment to the study. COVID-19, corona virus disease of 2019 of 14.4 points and the PISQ-12 entailing an MID of 10.6 points, thus requiring a sample size of 54 patients in each group to reach statistical significnace [23-25].

\section{Results}

Of the 183 women screened for the study, 134 were found eligible and willing to participate, of whom 131 were included in the final analysis. Three women from the study group, and none from the control group, were lost to follow-up because of COVID-19 restrictions and regulations (Fig. 1). Demographic and basic medical characteristics did not differ between the groups (Table 1). The mean age of the women in the study group was $51.8 \pm 3.5$ years compared to $52.3 \pm 3.9$ years in the control group. The respective mean BMI values were $26.5 \pm 4.2$ and $27.4 \pm 3.8 \mathrm{~kg} / \mathrm{m}^{2}$.

For the study and control groups, baseline values were similar for the positive cough test $(79.3 \%$ and $79.4 \%$, respectively, $P=0.66)$ and the mean $1-\mathrm{h}$ pad weight $(5.6 \pm 1.1$ and $5.8 \pm 1.2$, respectively, $P=0.72$ ).

The baseline UDI-6, ICIQ-UI and PISQ-12 scores were similar in both groups $(51.3 \pm 3.4$ vs. $52.4 \pm 10.9,9.4 \pm 3.2$ vs. $8.9 \pm 3.4,40.8 \pm 7.6$ vs. $41.4 \pm 6.9, P=0.57 / 0.61 / 0.53$, resectively) (Table 2).

Statistically significant improvement was demonstrated in the study compared to the control group at 3 months posttreatment in the objective measures of positive cough test (44.4\% vs. $79.4 \%, P=0.002$ ) and the mean 1 -h pad weight $(2.3 \pm 1.3$ vs. $5.6 \pm 1.1, P<0.001)$. Significant improvement was also observed in the study compared to the control group in the UDI-6, ICIQ-UI and the PISQ-12 scores $(24.7 \pm 9.1$ vs. $45.1 \pm 10.6, P=0.004 ; 16.5 \pm 3.3$ vs. $10.3 \pm 2.8$, $P=0.003$; and $21.3 \pm 6.8$ vs. $36.6 \pm 7.5, P=0.003$, respectively) (Table 3 ).

At 6 months post-treatment, the positive cough test and mean 1-h pad weight results and the results of the three questionnaires were similar in the study and control groups and were similar to baseline scores (Table 4).
Table 1 Demographic and medical information of the participants in the study

\begin{tabular}{llll}
\hline & Study group $(n=63)$ & Control group $(n=68)$ & $P$ value \\
\hline Age, mean (SD) & $51.8 \pm 3.5$ & $52.3 \pm 3.9$ & 0.78 \\
Post-menopausal women, no. (\%) & $7(11.1)$ & $9(13.2)$ & 0.37 \\
BMI, mean (SD) & $26.5 \pm 4.2$ & $27.4 \pm 3.8$ & 0.69 \\
Number of deliveries, median (range) & $3(1-5)$ & $3(1-5)$ & 0.85 \\
Diabetes, prevalence (\%) & $11(17.4 \%)$ & $13(19.1 \%)$ & 0.56 \\
Hypothyroidism, prevalence (\%) & $9(14.2 \%)$ & $10(14.7 \%)$ & 0.63 \\
Hypertension, prevalence (\%) & $13(20.6 \%)$ & $15(22.0 \%)$ & 0.51 \\
Hyperlipidemia, prevalence (\%) & $18(28.5 \%)$ & $18(26.4 \%)$ & 0.58 \\
Time from previous laser treatments, & $6.2(0.3)$ & $6.3(0.2)$ & 0.82 \\
months, mean (SD) & & & \\
\hline
\end{tabular}


Table 2 Comparisons between the study and control groups for the cough test, pad weight test and total scores on the UDI6, ICIQ-UI and PISQ-12 questionnaires prior to laser treatment

\begin{tabular}{lllll}
\hline & Study group $(n=63)$ & Control group $(n=68)$ & $\begin{array}{l}\text { Odds ratio (confi- } \\
\text { dence interval) }\end{array}$ & $p$ value \\
\hline Positive cough test; $n,(\%)$ & $50(79.3)$ & $54(79.4)$ & $0.99(0.76-1.34)$ & 0.66 \\
Pad weight (g); mean (SD) & $5.6(1.1)$ & $5.8(1.2)$ & $0.96(0.64-1.45)$ & 0.72 \\
UDI-6; mean (SD) & $51.3(13.4)$ & $52.4(10.9)$ & $0.97(0.59-1.55)$ & 0.57 \\
ICIQ-UI; mean (SD) & $9.4(3.2)$ & $8.9(3.4)$ & $1.05(0.51-2.29)$ & 0.61 \\
PISQ-12; mean (SD) & $40.8(7.6)$ & $41.4(6.9)$ & $0.98(0.68-1.40)$ & 0.53 \\
\hline
\end{tabular}

\begin{tabular}{lllll}
\hline & Study group $(n=63)$ & Control group $(n=68)$ & $\begin{array}{l}\text { Odds ratio (confi- } \\
\text { dence interval) }\end{array}$ & $P$ value \\
\hline Positive cough test; $n,(\%)$ & $28(44.4 \%)$ & $54(79.4 \%)$ & $0.56(0.29-0.83)$ & 0.0015 \\
Pad weight(g); mean (SD) & $2.3(1.3)$ & $5.6(1.1)$ & $0.41(0.15-0.80)$ & $<0.0001$ \\
UDI-6; mean (SD) & $24.7(9.1)$ & $45.1(10.6)$ & $0.54(0.28-0.97)$ & 0.004 \\
ICIQ-UI; mean (SD) & $16.5(3.3)$ & $10.3(2.8)$ & $1.60(1.01-2.64)$ & 0.003 \\
PISQ-12; mean (SD) & $21.3(6.8)$ & $36.6(7.5)$ & $0.58(0.32-0.96)$ & 0.003 \\
\hline
\end{tabular}

\begin{tabular}{lllll}
\hline & Study group $(n=63)$ & Control group $(n=68)$ & $\begin{array}{l}\text { Odds ratio (confi- } \\
\text { dence interval) }\end{array}$ & $P$ value \\
\hline Positive cough test; $n(\%)$ & $48(76.1 \%)$ & $54(79.4 \%)$ & $0.95(0.71-1.37)$ & 0.27 \\
Pad weight(g); mean (SD) & $5.2(1.4)$ & $5.7(1.2)$ & $0.91(0.55-1.46)$ & 0.48 \\
UDI-6; mean (SD) & $49.8(10.5)$ & $52.9(11.8)$ & $0.94(0.60-1.48)$ & 0.35 \\
ICIQ-UI; mean (SD) & $8.8(3.6)$ & $8.6(3.1)$ & $1.03(0.44-2.25)$ & 0.64 \\
PISQ-12; mean (SD) & $39.7(6.6)$ & $41.5(7.2)$ & $0.96(0.68-1.35)$ & 0.51 \\
\hline
\end{tabular}

Table 3 Comparison between the study and control groups of the cough test, pad weight test and total scores on the UDI6, ICIQ-UI and PISQ-12 questionnaires at 3 months posttreatment
Table 4 Comparison between the study and control groups of the cough test, pad weight test and total scores on the UDI6, ICIQ-UI and PISQ-12 questionnaires at 6 months posttreatment
These results align with our study of 33 women that showed recurrence of SUI symptoms at 6 months following $\mathrm{CO}_{2}$ laser treatment [14]. Moreover, our results concur with previous studies that investigated the safety and efficacy of Er:YAG laser treatment on SUI. Those studies also demonstrated a treatment effect on SUI symptoms at 3 months post-treatment, with recurrence of SUI at 6 months post-treatment. [16-18, 22-26]. Furthermore, the temporary and short-term effects of $\mathrm{CO}_{2}$ laser treatment have been demonstrated in studies for various other gynecological indications [27-30], thus supporting the temporariness of the effects, regardless of the indication for treatment.

Our results might suggest a correlation between the number of treatments and the length of treatment effect. However, due to the lack of proper studies on the effect of maintenance laser treatments, other interpretations should be considered. Our results suggest that our treatment might be valuable for women who accept the short-term nature of its benefits.

Since the reason for the shorter effect cannot be currently concluded, the optimal regimen for maintenance laser treatments cannot be determined. Further RCTs are required to assess the efficacy and safety of additional 
maintenance laser treatments and the optimal regimen of treatment, including the number of treatments and the time interval between treatments. More work is needed to evaluate whether laser treatment efficacy decreases after additional treatments.

Long-term treatment safety requires further evaluation as well. The majority of adverse events previously reported were considered local, mild and self-limiting [18, 27, 28]; however, long-term sequelae have been reported [27, 28]. Information is lacking regarding the effect of additional maintenance treatments on the rate of adverse events. Our study results demonstrate no difference in the short-term adverse event rates between the study and placebo groups, suggesting that a single additional maintenance laser treatment for SUI is a safe procedure. In addition, the rate of short-term mild adverse events was similar to that of the same group of women in their previous laser treatments [14]. Further research is required to evaluate the rate of longterm adverse events following repeated treatment sessions, especially in the setting of repeated treatments $2-3$ times yearly (every 3-6 months) and even more if the symptoms require a more intensive treatment regimen. These speculated risks may include chronic irritation of both the vaginal and cervical tissue that may lead to discharge and potential damage to daily function including sexual function, possible local malignant effects and perhaps a higher susceptibility to human papilloma virus.

From a cost-effectiveness point of view, it is important to mention that laser treatments for gynecological indications are not reimbursed or recognized by health care service providers in the country where the study was conducted. Average pricing among facilities and physicians that offer these services in the country where the study was conducted is around $\$ 3000$ US for the preliminary three laser treatments and $\$ 1000$ US for any additional maintenance treatments. Thus, the cost of continuing treatment may weigh on patients who experience the typical deterioration 3-6 months after each maintenance treatment session.

The strengths of the current study include a randomizedsham controlled trial design, which included only women who had previously experienced significant improvement in SUI symptoms after laser treatment. In addition, the current study utilized both objective and subjective evaluation tools to determine changes after laser treatment. Cough test results and pad weight were evaluated by a single gynecologist who was blinded to the study intervention allocation.

Study limitations include the heterogeneity of the study group, which comprised both pre- and post-menopausal women. Therefore, the results of our study should be interpreted with caution regarding $\mathrm{CO}_{2}$ laser treatment in populations of younger women. In addition, because all the study participants had had experience with sensations around laser treatment sessions, and though most participants in both their past and current treatments did not report any overt pain or discomfort during the treatments, there is still a possibility that the women in the sham group could have felt some sensation differences that could have led to bias in study results. An additional limitation to the study is the fact that women using local or systemic estrogen were excluded; thus, the study results may not be generalizable for the population of women being co-treated with local or systemic estrogen and laser.

Our results suggest that a single maintenance laser treatment for reducing symptoms of SUI in women for whom laser treatment previously showed a temporary significant improvement is a transiently effective, well-tolerated and safe procedure. This treatment modality provides alternative non-surgical treatment for women with this condition. Further research is warranted to establish the optimal regimen, including the timing and quantity of maintenance laser treatments, and to further assess long-term safety profiles.

Authors contribution R Lauterbach: project development, manuscript writing.

S Aharoni: manuscript writing.

N Farago: Data collection.

N Justman: manuscript editing, data analysis.

I Grunwald: project development.

L Lowenstein: project development and manuscript editing and writing.

\section{Declarations}

Conflict of interest None.

\section{References}

1. Cervigni M, Gambacciani M. Female urinary stress incontinence. Climacteric. 2015;18(Suppl 1):30.

2. Kalejaiye O, Vij M, Drake MJ. Classification of stress urinary incontinence. World J Urol. 2015;33:1215.

3. Itkonen Freitas A-M, Rahkola-Soisalo P, Mikkola TS, Mentula M. Current treatments for female primary stress urinary incontinence. Climacteric. 2019;22:263.

4. Lim R, Liong ML, Leong WS, Khan NAK, Yuen KH. Effect of stress urinary incontinence on the sexual function of couples and the quality of life of patients. J Urol. 2016;196:153.

5. Tozun M, Ayranci U, Unsal A. Prevalence of urinary incontinence among women and its impact on quality of life in a semirural area of Western Turkey. Gynecol Obstet Investig. 2009;67:241.

6. Lavelle ES, Zyczynski HM. Stress urinary incontinence: comparative efficacy trials. Obstet Gynecol Clin N Am. 2016;43:45.

7. Verghese T, Latthe P. Recent status of the treatment of stress urinary incontinence. Int J Urol. 2014;21:25.

8. Padmanabhan P, Dmochowski R. Urinary incontinence in women: a comprehensive review of the pathophysiology, diagnosis and treatment. Minerva Ginecol. 2014;66:469.

9. Fusco F, Abdel-Fattah M, Chapple CR, Creta M, La Falce S, Waltregny D, Novara G. Updated systematic review and meta-analysis 
of the comparative data on colposuspensions, pubovaginal slings, and midurethral tapes in the surgical treatment of female stress urinary incontinence. Eur Urol. 2017;72:567.

10. Mackova K, Van Daele L, Page A-S, Geraerts I, Krofta L, Deprest J. Laser therapy for urinary incontinence and pelvic organ prolapse: a systematic review. BJOG. 2020;127:1338.

11. Lauterbach R, Dabaja H, Matanes E, Gruenwald I, Lowenstein L. The efficacy and safety of $\mathrm{CO}_{2}$ laser treatment for sexual function and vaginal laxity improvement in pre-menopausal women. Lasers Surg Med. 2021;53:199.

12. Preti M, Vieira-Baptista P, Digesu GA, Bretschneider CE, Damaser M, Demirkesen O, Heller DS, Mangir N, Marchitelli C, Mourad S, Moyal-Barracco M, Peremateu S, Tailor V, Tarcan T, De Elise JB, Stockdale CK. The clinical role of laser for vulvar and vaginal treatments in gynaecology and female urology: a best practice document. J Low Genit Tract Dis. 2019;23:151.

13. Walter J-E, Larochelle A, No. 358-intravaginal laser for genitourinary syndrome of menopause and stress urinary incontinence. $\mathrm{J}$ Obstet Gynaecol Can. 2018;40:503.

14. Dabaja H, Lauterbach R, Matanes E, Gruenwald I, Lowenstein L. The safety and efficacy of $\mathrm{CO}_{2}$ laser in the treatment of stress urinary incontinence. Int Urogynecol J. 2020;31:1691.

15. Wallace SL, St Martin B, Lee K, Sokol ER. A cost-effectiveness analysis of vaginal carbon dioxide laser therapy compared with standard medical therapies for genitourinary syndrome of menopause-associated dyspareunia. Am J Obstet Gynecol. 2020;223:890.e1.

16. Behnia-Willison F, Nguyen TTT, Mohamadi B, Vancaillie TG, Lam A, Willison NN, Zivkovic J, Woodman RJ, Skubisz MM. Fractional $\mathrm{CO}_{2}$ laser for treatment of stress urinary incontinence. Eur J Obstet Gynecol Reprod Biol X. 2019;1:100004.

17. Franić D, Fistonić I, Franić-Ivanišević M, Perdija Ž, Križmarić M. Pixel $\mathrm{CO}_{2}$ laser for the treatment of stress urinary incontinence: a prospective observational multicenter study. Lasers Surg Med. 2021;53:514

18. González Isaza P, Jaguszewska K, Cardona JL, Lukaszuk M. Long-term effect of thermoablative fractional $\mathrm{CO}_{2}$ laser treatment as a novel approach to urinary incontinence management in women with genitourinary syndrome of menopause. Int Urogynecol J. 2018;29:211.

19. Alcalay M, Ben Ami M, Greenshpun A, Hagay Z, Schiff E. Fractional-pixel $\mathrm{CO}_{2}$ laser treatment in patients with urodynamic stress urinary incontinence: 1-year follow-up. Lasers Surg Med. 2021;53(7):960-967. https://doi.org/10.1002/lsm.23329.

20. Romero Otero J, Lauterbach R, Aversa A, Can Serefoglu E, Garcia B, Pamhan A, Skrodzka M, Krychman M, Reisman Y, Corona G, Lowenstein L. Laser-Based Devices for Female Genito-Urinary Indications - "Vaginal Rejuvenation": Position Statements from the European Society of Sexual Medicine (ESSM).
21. Shobeiri SA, Kerkhof MH, Minassian VA, Bazi T. And IUGA Research and Development Committee, IUGA Committee Opinion: Laser-based vaginal devices for treatment of stress urinary incontinence, genitourinary syndrome of menopause, and vaginal laxity. Int Urogynecol J. 2019;30:371.

22. US Food and Drug Administration. FDA warns against use of energy-based devices to perform vaginal "rejuvenation" or vaginal cosmetic procedures [internet]. FDA safety Communications. 2018. Available from https://www.fda.gov/MedicalDevices/ Safety/AlertsandNotices/ucm615013.htm.

23. Barber MD, Spino C, Janz NK, Brubaker L, Nygaard I, Nager CW, Wheeler TL. Pelvic Floor Disorders Network. The minimum important differences for the urinary scales of the Pelvic Floor Distress Inventory and Pelvic Floor Impact Questionnaire. Am J Obstet Gynecol. 2009;200(5):580.e1-7. https://doi.org/10.1016/j. ajog.2009.02.007.

24. Blaganje M, Śćepanović D, Žgur L, Verdenik I, Pajk F, Lukanović A. Non-ablative Er:YAG laser therapy effect on stress urinary incontinence related to quality of life and sexual function: a randomized controlled trial. Eur J Obstet Gynecol Reprod Biol. 2018;224:153.

25. Palacios S, Ramirez M. Efficacy of the use of fractional CO2RE intima laser treatment in stress and mixed urinary incontinence. Eur J Obstet Gynecol Reprod Biol. 2020;244:95.

26. Lin K-L, Chou S-H, Long C-Y. Effect of Er:YAG laser for women with stress urinary incontinence. Biomed Res Int. 2019;2019:7915813.

27. Pieralli A, Fallani MG, Becorpi A, Bianchi C, Corioni S, Longinotti M, Tredici Z, Guaschino S. Fractional $\mathrm{CO}_{2}$ laser for vulvovaginal atrophy (VVA) dyspareunia relief in breast Cancer survivors. Arch Gynecol Obstet. 2016;294:841.

28. Arroyo C. Fractional $\mathrm{CO}_{2}$ laser treatment for vulvovaginal atrophy symptoms and vaginal rejuvenation in Perimenopausal women. Int J Women's Health. 2017;9:591.

29. Pagano T, De Rosa P, Vallone R, Schettini F, Arpino G, De Placido S, Nazzaro G, Locci M, De Placido G. Fractional microablative $\mathrm{CO}_{2}$ laser for vulvovaginal atrophy in women treated with chemotherapy and/or hormonal therapy for breast Cancer: a retrospective study. Menopause. 2016;23:1108.

30. Gambacciani M, Levancini M. Vaginal erbium laser as secondgeneration thermotherapy for the genitourinary syndrome of menopause: a pilot study in breast Cancer survivors. Menopause. 2017;24:316.

Publisher's note Springer Nature remains neutral with regard to jurisdictional claims in published maps and institutional affiliations. 